\title{
RESEARCH
}

\section{Selective serotonin reuptake inhibitors for unipolar depression: a systematic review of classic long-term randomized controlled trials}

\author{
Dorian Deshauer MD MSc, David Moher PhD, Dean Fergusson PhD, Ester Moher BA, \\ Margaret Sampson MLIS, Jeremy Grimshaw MD PhD
}

$\infty$

See related article page $\mathrm{I} 3 \mathrm{I} 3$

\section{ABSTRACT}

Background: Selective serotonin reuptake inhibitors are increasingly used in the long-term treatment of depression. Much of the supporting evidence about the effects of these drugs comes from discontinuation trials, a variant of randomized controlled trials whose design is problematic to interpret. We conducted a systematic review to examine the efficacy and acceptability of long-term therapy with selective serotonin reuptake inhibitors relative to placebo in the treatment of unipolar depression.

Methods: We identified placebo-controlled randomized trials with a treatment duration of at least 6 months by searching MEDLINE, EMBASE and the Cochrane Central Register of Controlled Trials to update a recently published systematic review. Efficacy was defined in terms of response to treatment ( $50 \%$ improvement in depression score relative to baseline) and remission (score of 7 or below on the Hamilton rating scale for depression). Key secondary outcomes included quality of life, return to work, need for additional treatment and self-harm. Overall acceptability was defined in terms of dropouts for any reason over a course of treatment.

Results: Of the 2693 records identified initially, we included 6 randomized controlled trials that met our eligibility criteria. These studies had a moderate risk of bias, had assigned a total of 1299 participants with depression to either treatment or placebo and had followed both groups for 6-8 months. We observed statistically significant improvements in response to treatment (odds ratio [OR] 1.66, 95\% confidence interval [CI] 1.12-2.48), but not in remission (OR 1.46, 95\% Cl 0.92-2.32) or acceptability (OR $0.87,95 \% \mathrm{Cl} 0.67-1.14$ ). The effects appeared greater among patients without comorbidities.

Interpretation: There is a lack of classic randomized controlled trials of serotonin reuptake inhibitors lasting more than 1 year for the treatment of depression. The results of our systematic review support current recommendations for 6-8 months of antidepressant treatment following initial recovery but provide no guidance for longer treatment.

Une version française de ce résumé est disponible à l'adresse www.cmaj.ca/cgi/content/full/I78/Io/I293/DCI

CMAJ 2008;178(10):1293-30I
$\mathrm{O}$ ver the past decade, the use of selective serotonin reuptake inhibitors for the management of depression has increased dramatically, and preliminary evidence suggests that long-term use, for more than I or 2 years, accounts for much of this rise. ${ }^{1-3}$ Clinical practice guidelines generally recommend a 6- to 9-month course following initial recovery after a first episode of depression and longer, sometimes indefinite, therapy after subsequent episodes, to prevent relapse..$^{4-10}$

Long-term randomized controlled trials of antidepressants have typically used I of 2 possible designs, each answering different questions (Figure I). ${ }^{11}$ The most widely used design is called the "discontinuation trial," a 2-phase study in which all participants are initially treated with an open (unblinded) course of drug therapy. Participants attaining a certain response during the open-treatment phase enter the second phase, during which they are randomly assigned to continue active drug treatment or to receive placebo. ${ }^{12-14}$ Discontinuation trials are believed to minimize the number of participants with depression who must be exposed to placebo. This advantage comes at a cost, since the results apply only to patients with a response to the medication, not to those who experience spontaneous recovery; furthermore, withdrawal symptoms may lead to an overestimate of the true effect of the medication. When this design is used to test long-term therapy with selective serotonin reuptake inhibitors for the treatment of depression, the results are difficult to interpret with confidence because rates of spontaneous recovery in depression are potentially high and because withdrawal effects can mimic depression. ${ }^{13-15}$

The second type of randomized trial used to test longterm therapy with selective serotonin reuptake inhibitors is a 2-arm parallel randomized controlled trial, hereafter referred to as a classic randomized controlled trial (Figure I). ${ }^{16}$ In this type of trial, participants with acute depression

From the Department of Psychiatry (Deshauer) and the Department of Epidemiology and Community Medicine (D. Moher, Fergusson, Grimshaw), University of Ottawa, Ottawa, Ont.; the Department of Psychology (E. Moher), University of Waterloo, Waterloo, Ont.; and the Chalmers Research Group (D. Moher, Sampson), Ottawa, Ont. 


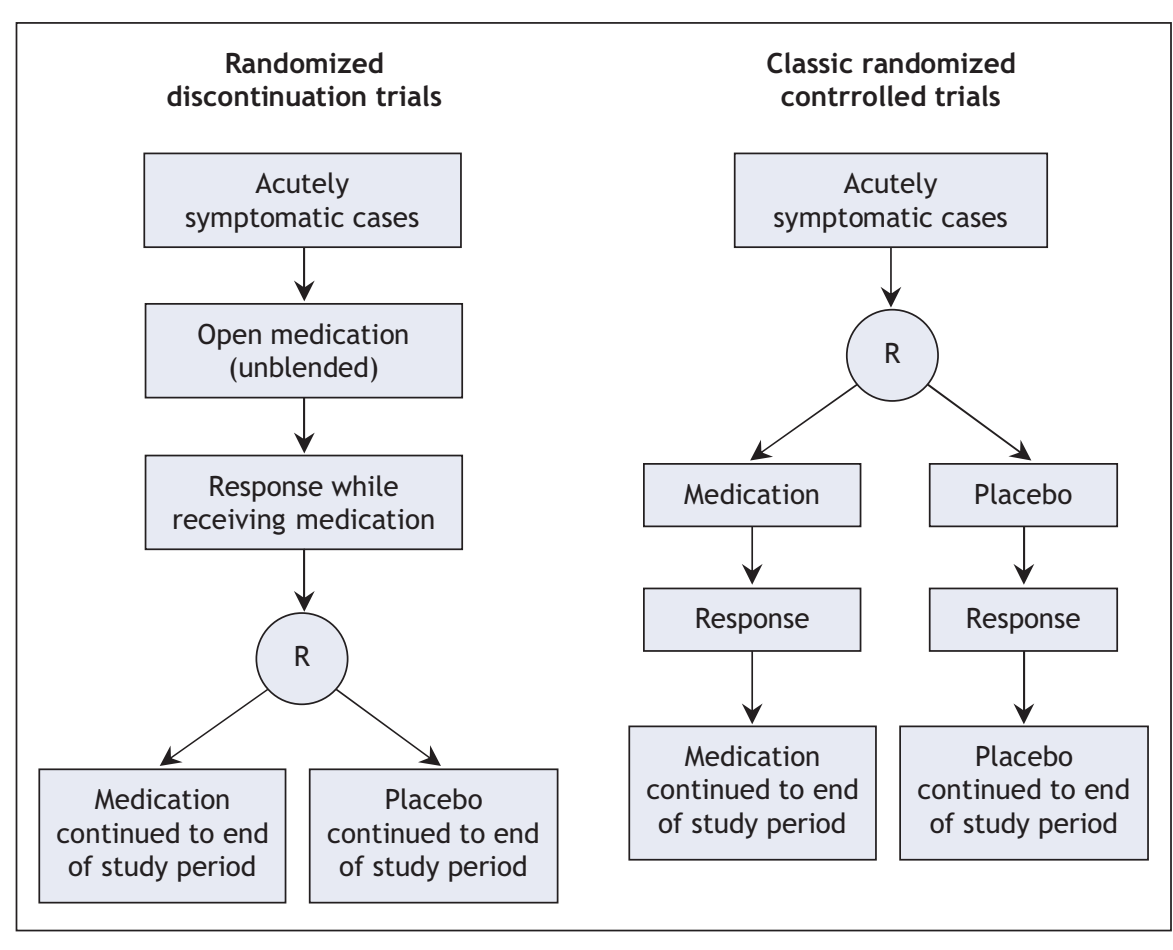

Figure 1: Two designs of randomized controlled trials used to investigate long-term antidepressant therapy.

\section{Methods}

\section{Literature search}

We searched for trials of fluoxetine, citalopram, escitalopram, fluvoxamine, paroxetine and sertraline. We updated the search strategy used in the previous systematic review of selective serotonin reuptake inhibitors and suicide ${ }^{17}$ to capture material indexed since the previous search date in MEDLINE (Ovid MEDLINE, to first week of May 2007) or EMBASE (Ovid EMBASE, to week I 8 of 2007). The EMBASE search was limited to journals not indexed in MEDLINE. ${ }^{18}$ We searched the Cochrane Central Register of Controlled Trials for any studies published from 2003 to the second quarter of 2007 . The search strategy combined the index terms associated with "serotonin uptake inhibitors" and the text terms "SSRI," "fluoxetine," "Prozac," "sertraline," "Zoloft," "paroxetine," "Paxil," "fluvoxamine," "Luvox," "citalopram" and "Celexa"; we used the revised highly sensitive search strategy for controlled trials for the MEDLINE

are assigned to receive either placebo or active drug, and all those achieving a certain response, either to the drug or to the placebo, are followed. The advantage of classic randomized controlled trials is that data from all participants contribute to our understanding of the drug's real-world effectiveness. Their main drawback is that a greater number of acutely ill people may have to receive placebo than in a discontinuation trial. ${ }^{13}$ Most classic trials of antidepressants are short-term studies. Fergusson and colleagues, ${ }^{17}$ in a systematic review examining selective serotonin reuptake inhibitors and suicide, identified 702 classic trials involving a total of $184 \mathrm{I} 3$ participants, the majority of which $(93 \%)$ lasted less than 6 months.

A recent systematic review based mainly on studies with discontinuation designs showed that, in a subgroup of patients who experienced recovery while taking medications, long-term therapy with selective serotonin reuptake inhibitors reduced the chances of relapse by up to $70 \%$ for up to 36 months, relative to patients whose therapy was discontinued earlier. ${ }^{6}$ However, there has been no systematic review of classic randomized trials of long-term therapy with this drug class to determine the potential benefits in all patients with depression, including those with spontaneous recovery.

We sought to examine the efficacy and acceptability of long-term therapy with selective serotonin reuptake inhibitors relative to placebo in the treatment of moderate to severe depression, including subgroups of patients with major chronic health conditions. We also examined a number of key indicators of the quality of evidence and its clinical importance. search $^{19}$ and the Hedges balanced strategy for therapy for the EMBASE search..$^{20}$ The updated search strategy is presented in Appendix I (available online at www.cmaj.ca/cgi/content/full /178/I0/1293/DC2).

\section{Study selection}

To be eligible for this systematic review, trials had to involve patients who had a diagnosis of major depression (as defined by the Diagnostic and Statistical Manual of Mental Disorders, third edition, third edition revised, or fourth edition) and who were randomly assigned to receive monotherapy with a selective serotonin reuptake inhibitor or placebo according to the classic 2-arm parallel randomized controlled trial design. Trials reporting a I- to 2-week placebo run-in period were eligible, because such trials have been shown to yield unbiased estimates of effectiveness. ${ }^{21}$ We included participants 18 years of age or older. There were no comorbidity restrictions. Our definition of long-term treatment was treatment over a period of at least 6 months. Trials were limited to those published in English.

Two of us (D.D. and E.M.) checked the reference lists of all included studies for additional studies and secondary reports. Working independently, the same 2 coauthors checked search results to identify all suitable studies. Disagreement about trials to be included was resolved by consensus among 3 of the coauthors (J.G., D.M. and D.F).

\section{Data abstraction}

Standardized case-report forms were developed, pilot-tested and completed by 2 independent reviewers (D.D. and E.M.). The following data were abstracted: characteristics of study 
population, interventions, study design, detailed inclusion and exclusion criteria, outcomes (including response and remission criteria), number of participants who completed the study and number of dropouts for any reason, method(s) of data analysis and trial funding. To handle missing data for primary outcomes, we used the published last-observationcarried-forward approach.

\section{Assessment of risk of bias}

We used the latest version of the Cochrane risk-of-bias tool ${ }^{22}$ to assess the risk of bias in the included studies (see Appendix 2, available online at www.cmaj.ca/cgi/content/full/178/1o /I293/DC2). This instrument consists of 6 items. Two of the items assess the strength of the randomization process in preventing selection bias in the assignment of participants to interventions: adequacy of sequence generation and allocation concealment. The third item (blinding) assesses the influence of performance bias on the study results. The fourth item assesses the likelihood of incomplete outcome data, which raise the possibility of bias in effect estimates. The fifth item assesses selective reporting, the tendency to preferentially report statistically significant outcomes. It requires a comparison of published data with trial protocols, when such are available. The final item refers to other sources of bias that are relevant in certain circumstances, for example, in relation to trial design or setting. Examples include methodologic issues such as those related to crossover designs and early trial termination. ${ }^{23}$

\section{Outcomes}

A priori, we identified 3 primary outcomes: response by study outcome, as defined by a $50 \%$ improvement in depression score relative to baseline; remission, as defined by a conventional remission cut-point (a score of 7 or less on the Hamilton rating scale for depression); and total number of dropouts as a proxy measure of overall treatment acceptability. ${ }^{24}$ We were also interested in key secondary outcomes, such as quality of life; the need for rescue therapy, such as admission to hospital, psychotherapy, pharmacotherapy or electroconvulsive therapy; self-harm (including attempted and completed suicide); and back-to-work status.

\section{Data analysis}

For each study, we calculated the odds ratio (OR) for each of the primary outcomes (response, remission and dropouts) with either selective serotonin reuptake inhibitor or placebo. Where clinically appropriate, we combined data from studies to estimate the pooled OR and $95 \%$ confidence intervals (CIs) using a DerSimonian and Laird random-effects model. Subgroup analyses were planned according to the presence or absence of comorbidities. An OR value greater than $\mathrm{I}$ indicates that more events occurred among patients who received selective serotonin reuptake inhibitors than among those who received placebo, and vice versa for OR values less than I. Statistical consistency across randomized controlled trials was assessed by means of the $I^{2}$ statistic. Potential publication bias was determined by visual inspection of an inverted funnel plot.

\section{Results}

\section{Literature search}

We identified 2693 records, of which 2669 were eliminated after initial screening because of study duration, language of publication and relevance. The remaining 24 citations were added to 2I potentially eligible studies identified from the original systematic review ${ }^{17}$ for more detailed examination. Of the 45 eligible trials, we excluded 39. Thirty-two of these exclusions were based on study design (3I randomized discontinuation trials and I crossover trial). Six trials were excluded because they did not involve patients with diagnosed depression: 4 trials were for the prevention of poststroke depression, and 2 trials were for the prevention of depression in people who had experienced a response to antidepressant therapy. We excluded a I2-month classic randomized controlled trial because it involved only children and adolescents. (The excluded trials are listed in Appendix 3, available online at www.cmaj.ca/cgi/content/full/I78/Io/I293/DC2).

In the analyses reported here, we included 6 trials of $6-8$ months' duration in which a total of 1299 patients with moderate to severe depression were randomly assigned to receive antidepressant therapy or placebo ${ }^{25-30}$ (Figure 2, Table I).

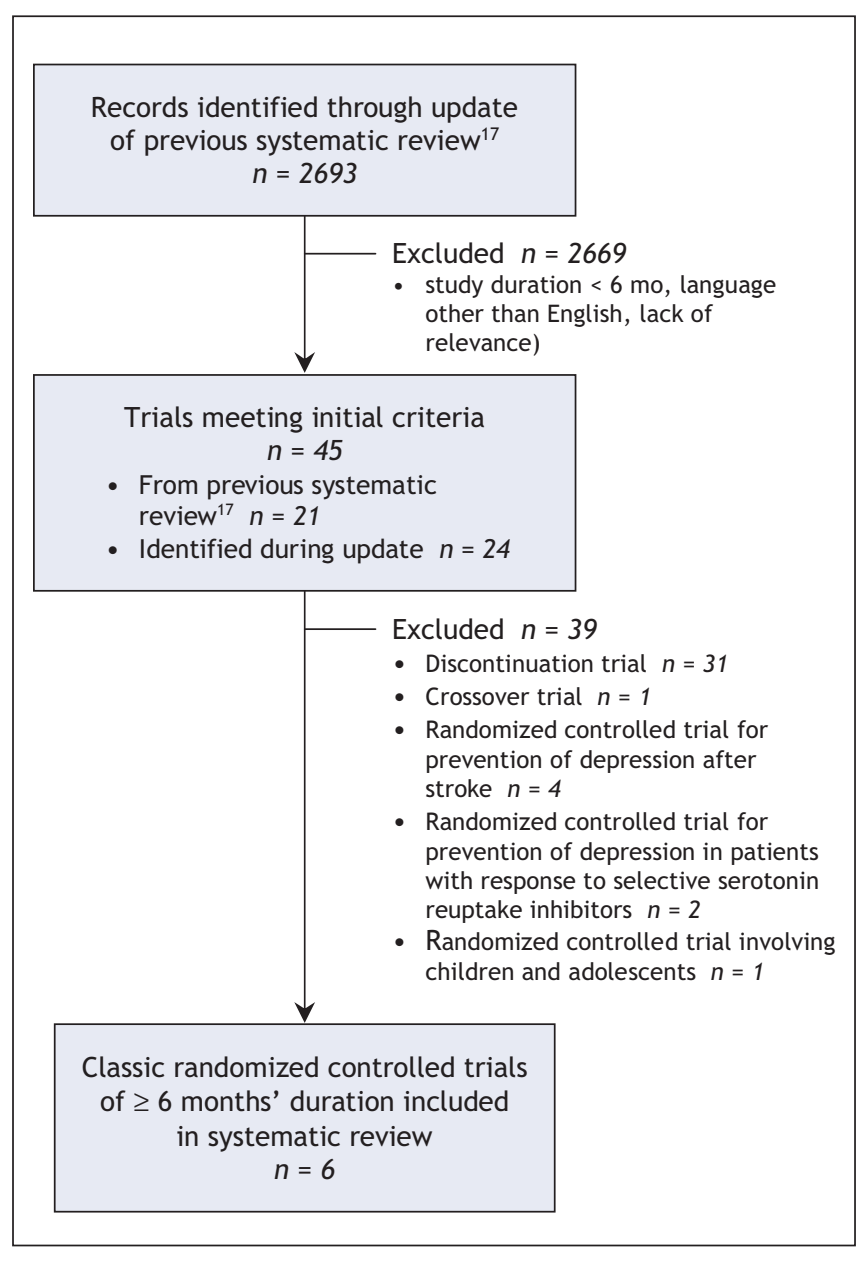

Figure 2: Flow diagram for identification of classic placebocontrolled randomized controlled trials. 


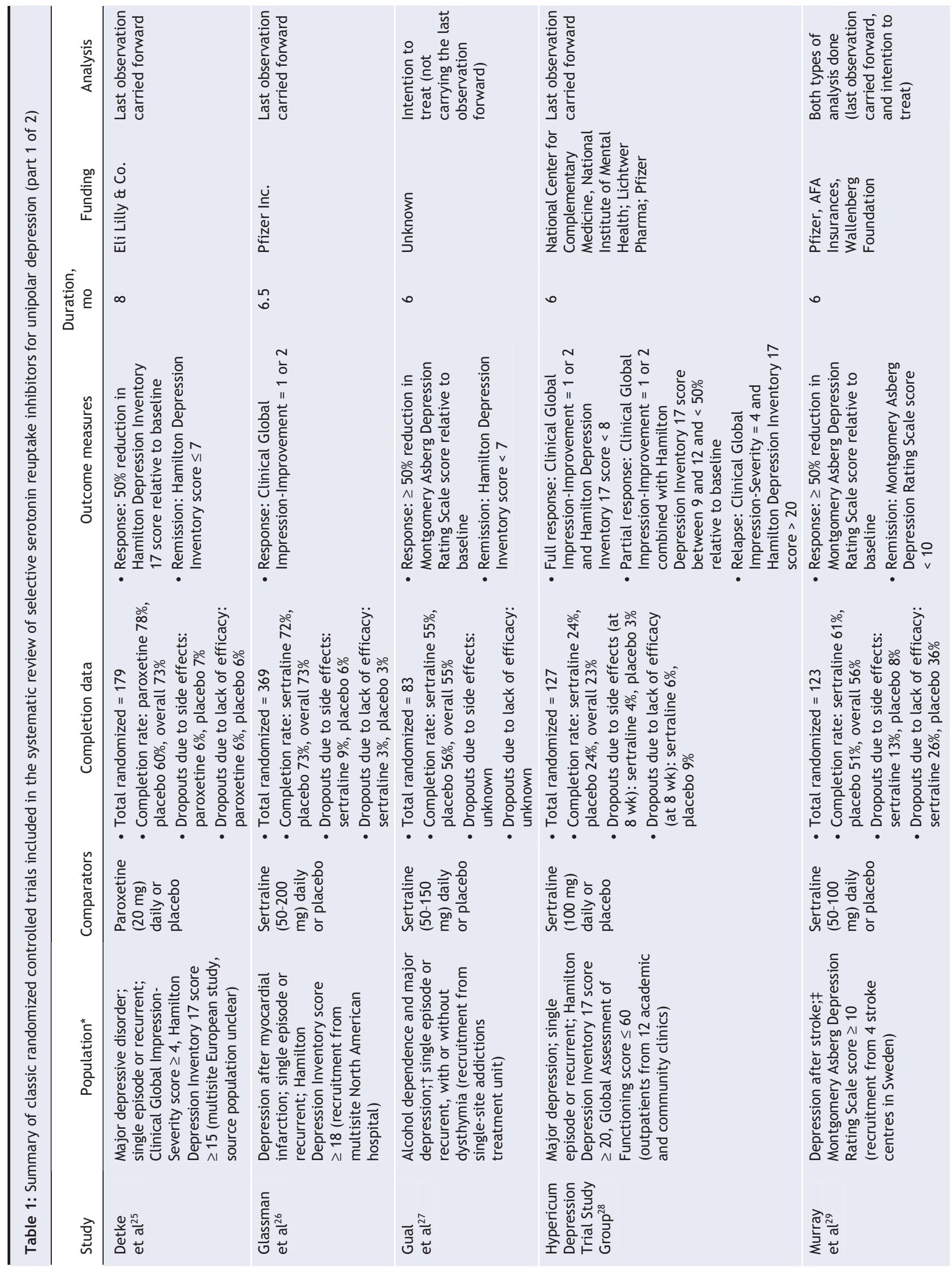




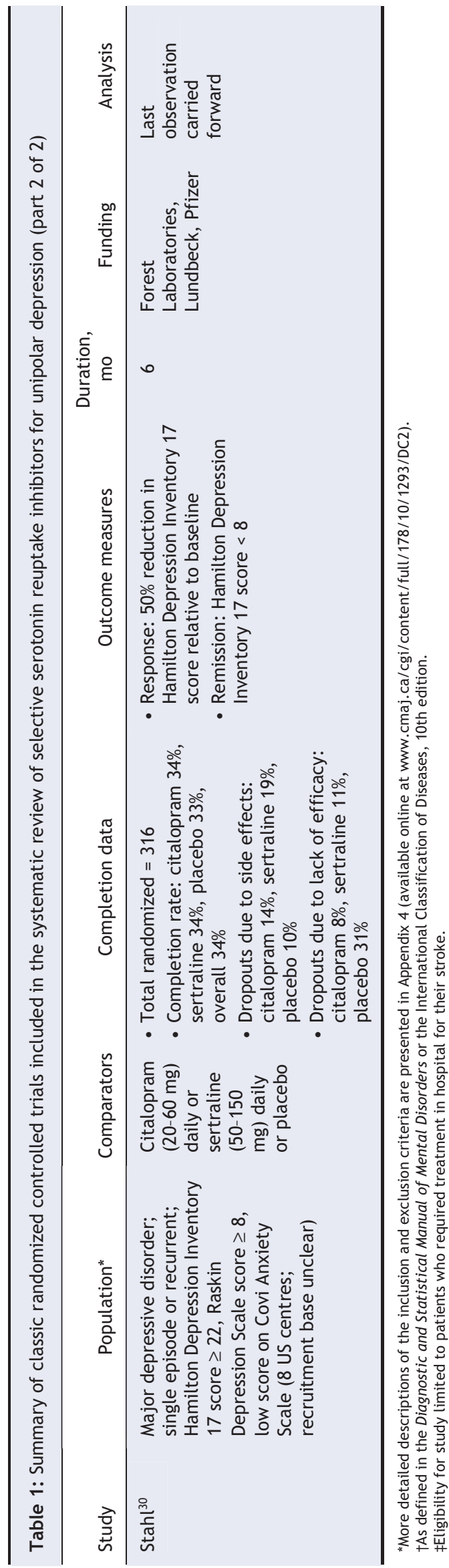

None of the eligible trials lasted longer than $\mathrm{I} 2$ months, and 5 of the 6 studies were commercially sponsored.

\section{Study populations}

Participants ranged in age from I8 to 89 years and had been recruited from psychiatric outpatient clinics, private research clinics and general medical wards or through public advertisements. In addition to participants with depression who were free of medical or psychiatric comorbidities, a range of clinical subgroups was represented, including participants with significant medical comorbidities (myocardial infarction, stroke) and alcohol dependence. Detailed inclusion and exclusion criteria of the 6 trials are summarized in Appendix 4 (available online at www.cmaj.ca/cgi/content/full/I78/Io /1293/DC2). In the 3 studies in which history of depression was reported, ${ }^{25,26,30} 20 \%-50 \%$ of participants had a history of recurrent depression.

\section{Interventions}

Participants were randomly assigned to receive placebo or a selective serotonin reuptake inhibitor, specifically sertraline $50-200 \mathrm{mg} / \mathrm{d},{ }^{26-30}$ citalopram $20-60 \mathrm{mg} / \mathrm{d}^{30}$ or paroxetine $20 \mathrm{mg} / \mathrm{d}^{25}$

\section{Assessment of risk of bias}

Overall, the mean dropout rate across all 6 trials was $48 \%$ (range $27 \%-77 \%$ ). For most of the included studies, we were unable to ascertain the risk of bias for several items because of poor reporting. Four of the included studies had unclear sequence generation, 3 had unclear allocation concealment, 2 had unclear blinding, and all had unclear selective outcome reporting. Four had a high risk of bias for incomplete outcome data, and 4 were assessed as unclear for "other biases" (Table 2). Visual inspection of the funnel plots did not suggest asymmetry (e.g., publication bias).

\section{Primary outcomes}

For response to treatment (50\% improvement in depression score relative to baseline), a pooled analysis of the 6 trials showed that selective serotonin reuptake inhibitors were superior to placebo at 6-8 months (OR I.66, 95\% CI I.I2-2.48; $I^{2}=63.9 \%$ ) (Figure 3). Subgroup analysis showed a statistically significant treatment effect among patients with depression who had no comorbidities (OR 2.I3, 95\% CI I.II-4.08; $I^{2}=76.8 \%$ ) but not among those who had comorbidities (OR I.32, 95\% CI o.84-2.06; $I^{2}=30.8 \%$ ) (Figure 3).

We obtained data on remission (score of 7 or below on the Hamilton rating scale for depression) from 4 trials. ${ }^{25,27,29,30}$ Overall, the pooled difference between selective serotonin reuptake inhibitors and placebo was not statistically significant (OR I.46, 95\% CI 0.92-2.32; $P^{2}=38 \%$ ). However, participants without comorbidities had a significantly higher remission rate if they were taking selective serotonin reuptake inhibitors than if they were taking placebo (OR 2.06, 95\% CI I.4I-3.0I; $I^{2}=0 \%$, whereas the difference for participants with comorbidities was not statistically significant (OR $0.87,95 \%$ CI $0.44^{-I} .72 ; I^{2}=0 \%$ ) (Figure 4 ).

For our measure of overall acceptability (total dropouts) 
Table 2: Assessment of risk of bias* in classic randomized controlled trials of selective serotonin reuptake inhibitors included in the systematic review

\begin{tabular}{|c|c|c|c|c|c|c|}
\hline Study & $\begin{array}{l}\text { Sequence } \\
\text { generation }\end{array}$ & $\begin{array}{c}\text { Allocation } \\
\text { concealment }\end{array}$ & Blinding & $\begin{array}{l}\text { Incomplete } \\
\text { outcome data }\end{array}$ & $\begin{array}{l}\text { Selective outcome } \\
\text { reporting }\end{array}$ & Other biases \\
\hline Detke et $\mathrm{al}^{25}$ & Unclear & Unclear & Low risk & High risk & Unclear & Unclear \\
\hline Gual et $\mathrm{al}^{27}$ & Low risk & Low risk & Unclear & High risk & Unclear & Low risk \\
\hline $\begin{array}{l}\text { Hypericum Depression Trial } \\
\text { Study Group }\end{array}$ & Low risk & Low risk & Low risk & Unclear & Unclear & Unclear \\
\hline Stahl ${ }^{30}$ & Unclear & Unclear & Low risk & High risk & Unclear & Unclear \\
\hline
\end{tabular}

${ }^{*}$ Ratings based on Cochrane risk-of-bias tool ${ }^{22}$ and explained in Appendix 2 (available online at www.cmaj.ca/cgi/content/full/178/10/1293/DC2).

there was no statistically significant difference between selective serotonin reuptake inhibitors and placebo (OR o.87, 95\% CI 0.67-I.I4; $P^{2}=2$ I. $3 \%$ ) (Figure 5).

\section{Secondary outcomes}

Five of the 6 trials reported quality of life at the end of the trial (Table 3). Because a range of measures was used, we did not pool the data. One of the 5 trials reported improvements in all domains of a multidomain quality-of-life score,${ }^{25}$ and another reported a quality-of-life summary statistic favouring selective serotonin reuptake inhibitors $(p<0.0 \mathrm{I})$, but the subscale breakdown was not reported. ${ }^{30} \mathrm{~A}$ third trial reported results of a $10-\mathrm{cm}$ visual analogue scale that favoured selective sero- tonin reuptake inhibitors, ${ }^{29}$ and a fourth reported quality-oflife improvements restricted to mood subscales ${ }^{27}$ with no statistically significant differences in other subscales. None of the trials provided information on the need for specific rescue therapies, including admission to hospital for psychiatric reasons, psychotherapy, pharmacotherapy or electroconvulsive therapy. Four trials did not specifically report on suicide or self-harm. ${ }^{26,27,29,30}$ In the 2 trials that reported on suicide or self-harm, there was a total of I completed suicide among patients receiving placebo and none among patients receiving selective serotonin reuptake inhibitor. ${ }^{25,28}$ Information on back-to-work status was not reported in any of the trials. One of the 6 trials stratified outcomes by the number of previous

\section{Study}

Drug, $n / N$ Placebo, $n / N \quad$ OR $(95 \% \mathrm{Cl})$

Depression with comorbidity

Glassman et $\mathrm{al}^{26} \quad 124 / 188$

Murray et $\mathrm{al}^{29} \quad 47 / 62$

97/183 $1.72(1.13-2.61)$

Gual et $\mathrm{al}^{27}$

$14 / 44$

Subtotal

$185 / 294$

$48 / 61$

$0.85(0.42-1.74)$

$11 / 39$

$1.19(0.46-3.05)$

$156 / 283$

$1.32(0.84-2.06)$

Depression without comorbidity

$\begin{array}{lccc}\text { Detke et } \mathrm{al}^{25} & 66 / 86 & 41 / 93 & 4.19(2.19-7.99) \\ \begin{array}{l}\text { Hypericum Depression } \\ \text { Trial Study Group }\end{array} & 53 / 111 & 50 / 116 & 1.21(0.71-2.04) \\ \text { Staht }^{30} & 121 / 209 & 43 / 107 & 2.05(1.27-3.29) \\ \text { Subtotal } & 240 / 406 & 134 / 316 & 2.13(1.11-4.08) \\ \text { Overall } & 425 / 700 & 290 / 599 & 1.66(1.12-2.48)\end{array}$

Overall

$290 / 599$

$1.66(1.12-2.48)$

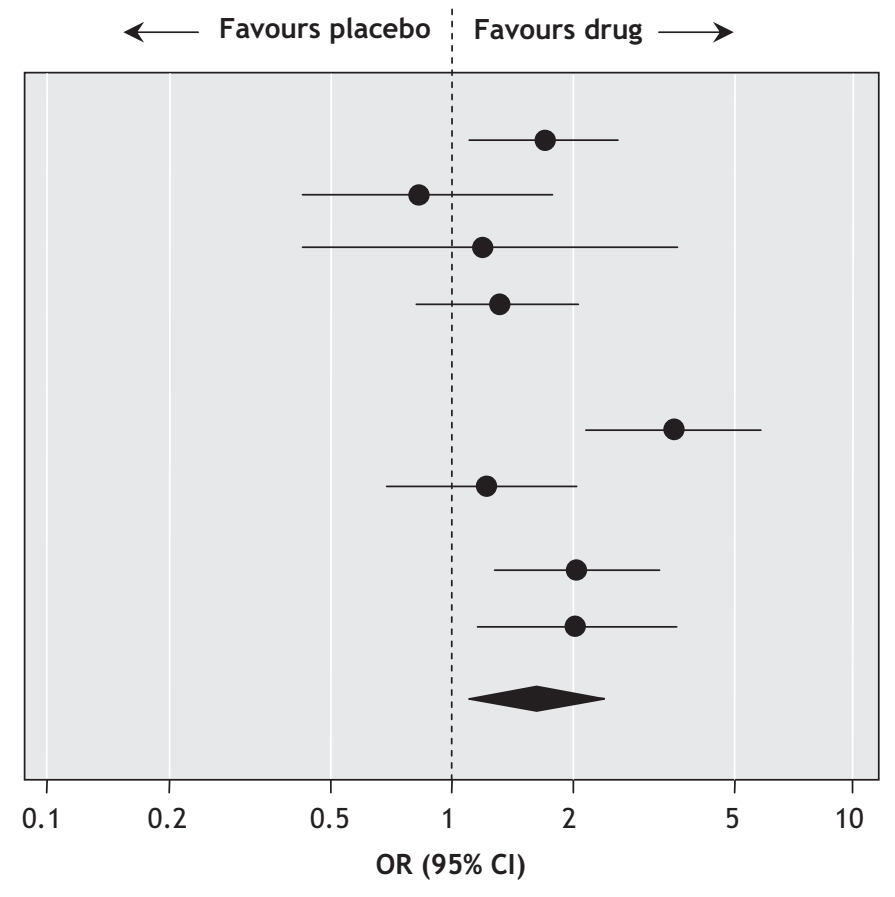

Figure 3: Pooled analysis of response to treatment (50\% improvement in depression score relative to baseline) in 6 classic randomized controlled trials of selective serotonin reuptake inhibitors in patients with major depression. The vertical line represents no difference between compared treatments. 
depressive episodes and reported a higher response rate among patients with a history of recurrent depression. ${ }^{26}$

\section{Interpretation}

No trials assessing the efficacy of selective serotonin reuptake inhibitor therapy over a period of more than I year met our eligibility criteria. Only 6 trials met our eligibility criteria; these studies, which had a moderate risk of bias, had randomly assigned a total of 1299 participants with depression to receive placebo or selective serotonin reuptake inhibitor and had followed both groups for 6-8 months. The mean dropout rate after 6-8 months was $48 \%$ (range $27 \%-87 \%$ ), which exceeds the $15 \%$ maximum previously recommended for studies lasting longer than 3 months. ${ }^{31}$ High dropout rates tend to reduce the level of confidence in the internal validity of trial results, as well as their applicability to general clinical practice. The only classic randomized clinical trial extending past 8 months that we identified was excluded from our review (see Appendix 3, at www.cmaj.ca/cgi /content/full/I78/Io/I293/DC2). That study involved children and adolescents with depression, and participants with a response to medication or placebo were followed for 12 months. However, with an overall completion rate of only I $6 \%$, the trial was difficult to evaluate.

We observed statistically significant improvements in response to treatment but not in remission or acceptability (which might have been due to lack of power) after 6-8 months of selective serotonin reuptake inhibitor therapy. The effects appeared greater in patients without comorbidities. However, given the limited reporting of participants' course of illness, we were unable to determine whether particular subgroups, such as those with highly recurrent depression, benefited more than those with single episodes. Furthermore, we found few data about the long-term effects of selective serotonin reuptake inhibitors on a range of important clinical outcomes, such as time off work, the need for cointerventions and self-harm, relative to those of placebo.

The study populations had been recruited from a range of settings, including psychiatric clinics, general medical hospitals and private community clinics. Groups with a higher prevalence of severe or recurrent depression may benefit most from antidepressants, and the distribution of more severe depressive illness may differ across these settings. ${ }^{32-34}$

One of the strengths of our systematic review is that it focused on classic long-term randomized controlled trials of selective serotonin reuptake inhibitors for the treatment of depression. Previous reviews included and were dominated by studies with discontinuation designs, which are difficult to interpret and which may overestimate the benefits of treatments.

Our study has several limitations. Because of resource constraints, we included only studies published in English, but this restriction is unlikely to have biased our results. ${ }^{35,36} \mathrm{We}$ did not detect any evidence of publication bias.

The main limitations of our review reflect the weaknesses of the included studies. The studies were at moderate risk of bias and failed to report key methodologic issues. No study reported data beyond $\mathrm{I} 2$ months. The most commonly reported outcome was "response to treatment" rather than "full remission." Response was defined in terms of a $50 \%$ improvement in depression scores relative to baseline, whereas "full remission" was defined by pre-established cut-points on depression scores. Full remission from depression correlates with better longer-term functional recovery, lower risk of relapse and

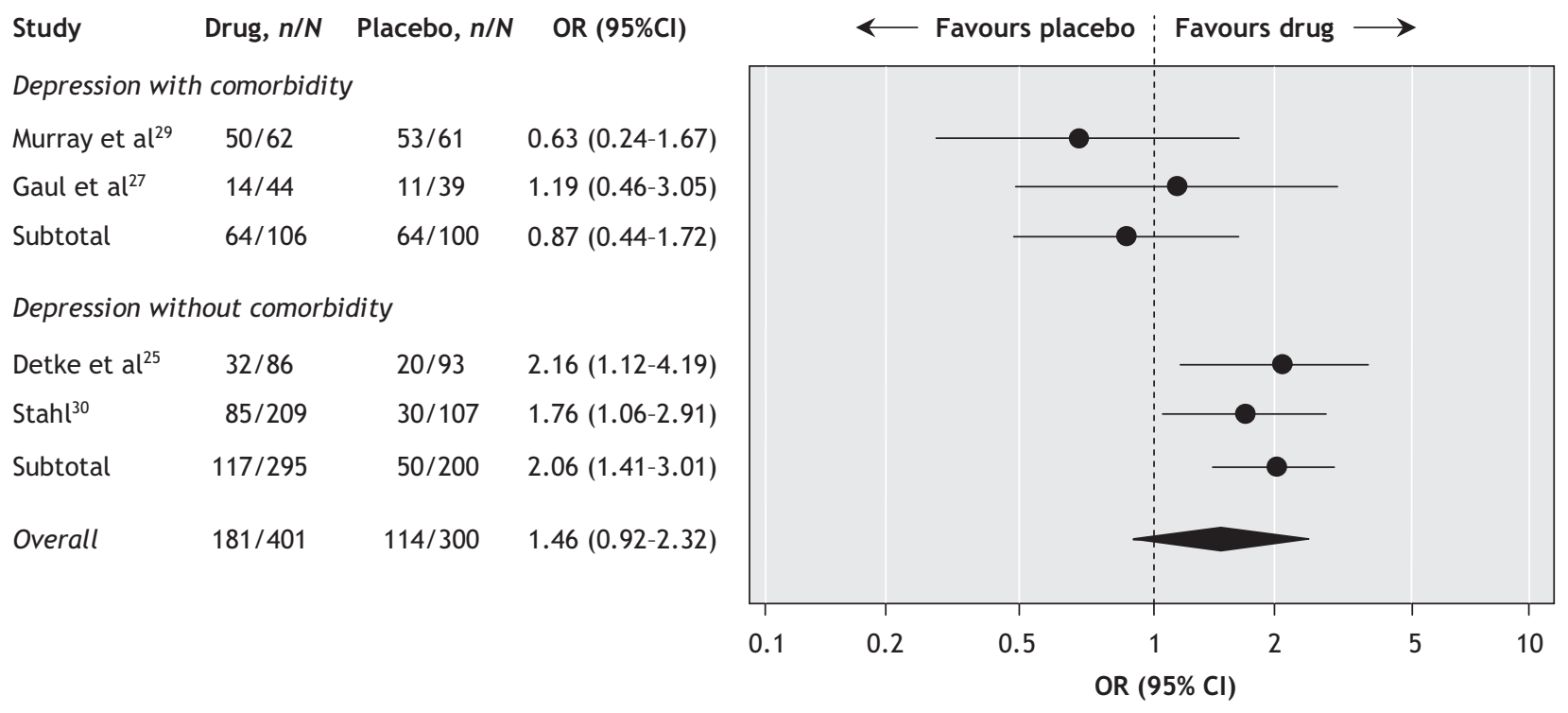

Figure 4: Pooled analysis of remission (score of 7 or below on the Hamilton rating scale for depression) in 4 classic randomized controlled trials of selective serotonin reuptake inhibitors in patients with major depression. The vertical line represents no difference between compared treatments. 
higher levels of patient satisfaction than partial response without remission. ${ }^{37}$ Another limitation is that 4 of the 6 included trials reported outcomes in terms of the "last observation carried forward," a method that may underestimate true treatment effects in short-term trials but overestimate active interventions in long-term trials. ${ }^{38}$ Five of the 6 studies were commercially sponsored. This might have led to an exaggeration of treatment effects, since industry-sponsored trials have been shown to be 4 times as likely as independent studies to demonstrate positive effects of the sponsor's drug. ${ }^{39-41}$

Similar to concerns with shorter-term trials of selective serotonin reuptake inhibitors, the study participants in the in- cluded trials may not be representative of those seen in everyday practice. ${ }^{42}$ For example, 5 of the 6 trials excluded patients with substance abuse, a common comorbidity, and all trials excluded patients with suicidal ideation, one of the diagnostic criteria for major depressive disorder in the Diagnostic and Statistical Manual of Mental Disorders, 4 th edition.

\section{Conclusion}

Despite the widespread use of long-term therapy with selective serotonin reuptake inhibitors, relatively few trials have compared long-term outcomes between patients with depres-

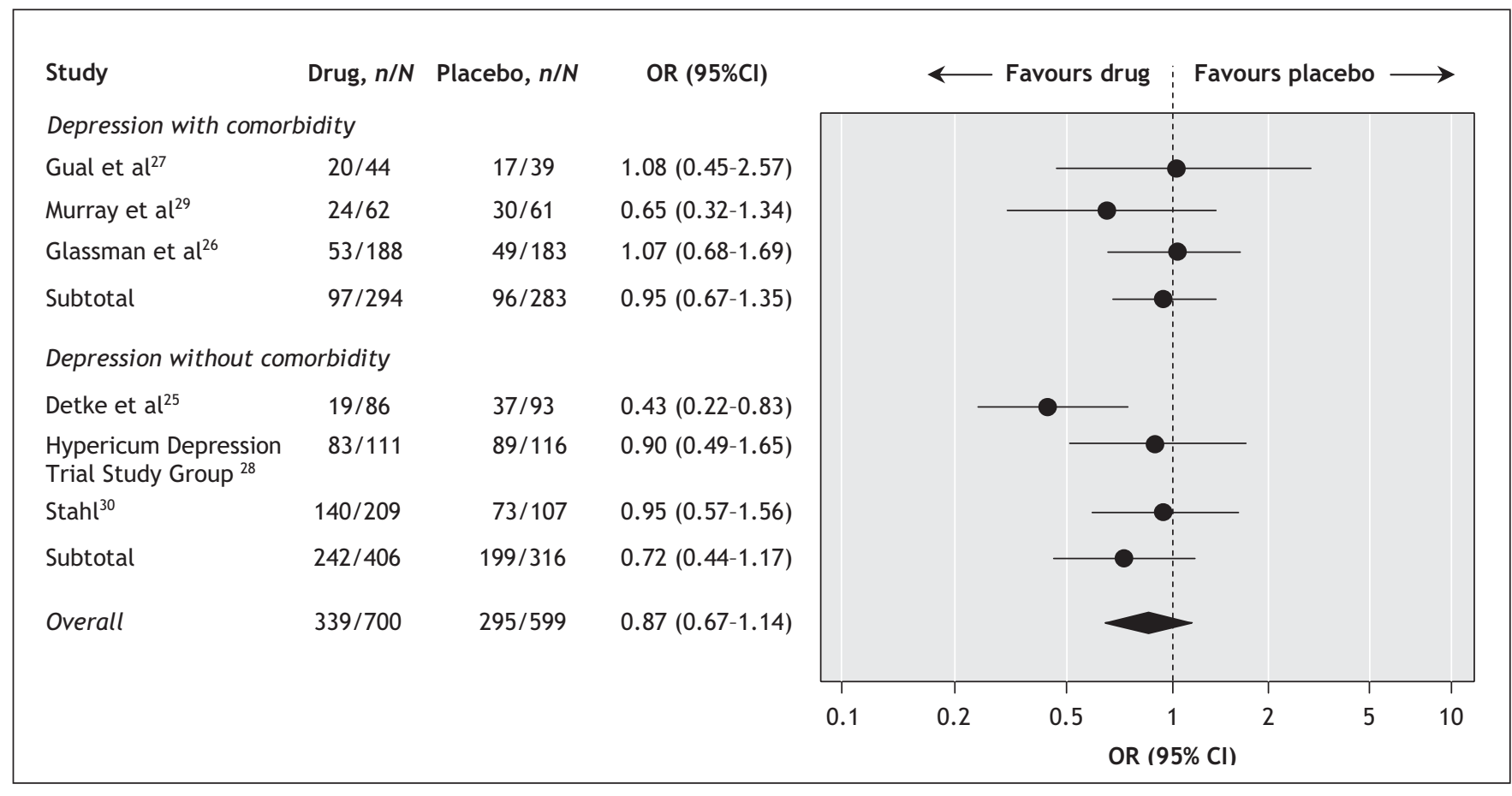

Figure 5: Pooled analysis of overall acceptability (total dropouts) in 6 classic randomized controlled trials of selective serotonin reuptake inhibitors in patients with major depression. The vertical line represents no difference between compared treatments.

Table 3: Secondary outcomes in classic randomized trials of selective serotonin reuptake inhibitors included in the systematic review

\begin{tabular}{|c|c|c|c|c|}
\hline Study & Rescue therapy* & Back-to-work status & $\begin{array}{l}\text { Suicide, suicide } \\
\text { attempt or self-harm }\end{array}$ & $\begin{array}{c}\text { Overall } \\
\text { quality-of-life }\end{array}$ \\
\hline Detke et $\mathrm{al}^{25}$ & Not reported & Not reported & 1 suicide (placebo group) & $\begin{array}{l}\text { Sheehan Disability Scale } \\
\text { (favoured drug) }\end{array}$ \\
\hline Glassman et $\mathrm{al}^{26}$ & Not reported & Not reported & Not reported & Not reported \\
\hline Gual et $\mathrm{al}^{27}$ & Not reported & Not reported & Not reported & $\begin{array}{l}\text { Medical Outcomes Study 36-item } \\
\text { Short Form (favoured drug) }\end{array}$ \\
\hline Murray et al ${ }^{29}$ & Not reported & Not applicable $†$ & Not reported & $\begin{array}{l}\text { Visual analogue scale (favoured } \\
\text { drug) }\end{array}$ \\
\hline Stahl ${ }^{30}$ & Not reported & Not reported & Not reported & $\begin{array}{l}\text { Symptom Checklist-56 (favoured } \\
\text { drug) }\end{array}$ \\
\hline
\end{tabular}

*Medications, psychotherapy, electroconvulsive therapy or admission to hospital.

†Mean age of participants (who had depression following stroke) was 70 years. 
sion who recover spontaneously and those who recover because of medication. Most treatment guidelines recommend a minimum of 6-9 months of antidepressant treatment following initial recovery from depression. Our observations, based on limited evidence, support current recommendations that treatment continue for at least $6-9$ months after recovery from an episode of depression, particularly in those without major comorbidities. Longer-term treatment should be undertaken only in selected cases and with an appreciation of the uncertainties surrounding the practice. Future studies should examine long-term use of selective serotonin reuptake inhibitors in depression using clinically relevant outcomes for all patients with depression, including those who experience spontaneous resolution.

This article has been peer reviewed.

Competing interests: None declared.

Disclaimer: Dorian Deshauer is a coauthor of this article. As an associate editor of $C M A J$, he was not involved in the selection of peer reviewers or the vetting of the manuscript before its acceptance.

Contributors: Dorian Deshauer, David Moher, Dean Fergusson and Jeremy Grimshaw contributed to designing the systematic review, performing the statistical analyses, interpreting the results and writing the manuscript. Dorian Deshauer, Dean Fergusson and Ester Moher contributed to the identification of studies. Dorian Deshauer and Ester Moher contributed to data abstraction. Margaret Sampson designed and implemented the search strategy. All of the authors critically revised the manuscript and approved the final version.

Acknowledgement: David Moher is funded by a University of Ottawa Research Chair.

\section{REFERENCES}

I. Raymond CB, Morgan SG, Caetano PA. Antidepressant utilization in British Columbia from 1996 to 2004: increasing prevalence but not incidence. Psychiatr Serv 2007;58:79-84.

2. Petty DR, House A, Knapp P, et al. Prevalence, duration and indications for prescribing of antidepressants in primary care. Age Ageing 2006;35:523-6.

3. Meijer WE, Heerdink ER, Leufkens HG, et al. Incidence and determinants of longterm use of antidepressants. Eur J Clin Pharmacol 2004;60:57-6I.

4. Depression: management of depression in primary and secondary care. London (UK): National Institute for Health and Clinical Excellence; 2004

5. Major depression in adults in primary care. Bloomington (MN): Institute for Clinical Systems Improvement; 2006.

6. Geddes JR, Carney SM, Davies C, et al. Relapse prevention with antidepressant drug treatment in depressive disorders: a systematic review. Lancet 2003;36r:653-6r.

7. Adult primary care depression guidelines. Oakland (CA): Care Management Institute, Kaiser Permanente; 2004

8. Canadian Psychiatric Association; Canadian Network for Mood and Anxiety Treatments (CANMAT). Clinical guidelines for the treatment of depressive disorders. Can J Psychiatry 200I;46(Suppl I):IS-92S.

9. American Psychiatric Association. Practice guideline for the treatment of patients with major depresive disorder (revision). Am J Psychiatry 2000;157(4 Suppl):I-45.

Io. Pharmacotherapy companion to the depression. Columbia (MD): American Medical Directors Association; 2005.

II. Zimmerman M, Posternak M, Ruggero C. Impact of study design on the results of continuation studies of antidepressants. J Clin Psychopharmacol 2007;27:177-8I.

I2. MacLehose RR, Reeves BC, Harvey IM, et al. Hybrid study designs and RCT variants. Health Technol Assess (Rockv) 2000;4:57-80.

I3. Kopec JA, Abrahamowicz M, Esdaile JM. Randomized discontinuation trials: utility and efficiency. JClin Epidemiol I993;46:959-7I.

I4. Greenhouse JB, Stangl D, Kupfer DJ, et al. Methodologic issues in maintenance therapy clinical trials. Arch Gen Psychiatry 1991;48:313-8.

I5. Baldwin DS, Cooper JA, Huusom AKT, et al. A double-blind, randomized, parallelgroup, flexible-dose study to evaluate the tolerability, efficacy and effects of treatment discontinuation with escitalopram and paroxetine in patients with major depressive disorder. Int Clin Psychopharmacol 2006;21:159-69.

I6. Mallinckrodt $\mathrm{C}$, Chuang-Stein $\mathrm{C}, \mathrm{McS}$ orley $\mathrm{P}$, et al. A case study comparing a ran- domized withdrawal trial and a double-blind long-term trial for assessing the long-term efficacy of an antidepressant. Pharm Stat 2007;6:0-22.

17. Fergusson D, Doucette S, Cranley Glass K, et al. Association between suicide attempts and selective serotonin reuptake inhibitors: systematic review of randomised controlled trials. BMJ 2005;330:396.

I8. Sampson M, McGowan J, Armour T, et al. Managing database overlap in systematic reviews using Batch Citation Matcher: case studies using Scopus. J Med Libr Assoc 2006;94:46I-3, e219.

I9. Glanville JM, Lefebvre C, Miles JN, et al. How to identify randomized controlled trials in MEDLINE: ten years on [published erratum appears in J Med Libr Assoc 2006;94:354]. J Med Libr Assoc 2006;94:130-6.

20. Wong SS, Wilczynski NL, Haynes RB. Developing optimal search strategies for detecting clinically sound treatment studies in EMBASE. JMed Libr Assoc 2006;94:4I-7.

2I. Lee S, Walker JR, Jakul L, et al. Does elimination of placebo responders in a placebo run-in increase the treatment effect in randomized clinical trials? A metaanalytic evaluation. Depress Anxiety 2004;19:10-9.

22. Higgins JPT, Green S, editors. Cochrane handbook for systematic reviews of interventions. Version 5.0.0 Oxford (UK): The Cochrane Collaboration; 2008 Feb. Available: www.cochrane-handbook.org (accessed 2008 May 23).

23. Montori VM, Devereaux PJ, Adhikari NKJ, et al. Randomized trials stopped early for benefit: a systematic review. JAMA 2005;294:2203-9.

24. Barbui C, Furukawa TA, Cipriani A. Effectiveness of paroxetine in the treatment of acute major depression in adults: a systematic re-examination of published and unpublished data from randomized trials. $C M A J$ 2008;178:296-305.

25. Detke MJ, Wiltse CG, Mallinckrodt $\mathrm{CH}$, et al. Duloxetine in the acute and longterm treatment of major depressive disorder: a placebo- and paroxetine-controlled trial. Eur Neuropsychopharmacol 2004; I4:457-70.

26. Glassman AH, O'Connor CM, Califf RM, et al. Sertraline treatment of major depression in patients with acute MI or unstable angina. JAMA 2002;288:70I-9.

27. Gual A, Balcells $M$, Torres $M$, et al. Sertraline for the prevention of relapse in detoxicated alcohol dependent patients with a comorbid depressive disorder: a randomized controlled trial. Alcohol Alcohol 2003;38:619-25.

28. Hypericum Depression Trial Study Group. Effect of Hypericum perforatum (St John's wort) in major depressive disorder; a randomized controlled trial. JAMA 2002;287:1807-I4

29. Murray V, von Arbin M, Barfai A et al. Double-blind comparison of sertraline and placebo in stroke patients with minor depression or less severe major depression. I Clin Psychiatry 2005;66:708-I6.

30. Stahl SM. Placebo-controlled comparison of the selective serotonin reuptake inhibitors citalopram and sertraline. Biol Psychiatry 2000;48:894-90I.

3I. Treatment of major depression. Vol. 2. Rockville (MD): US Department of Health and Human Services; Agency for Healthcare Policy and Research; 1993.

32. Chatwin J, Kendrick T; THREAD Study Group. Protocol for the THREAD (THREshold for AntiDepressants) study: a randomised controlled trial to determine the clinical and cost-effectiveness of antidepressants plus supportive care, versus supportive care alone, for mild to moderate depression in UK general practice. BMC Fam Pract 2007;8:2.

33. O'Connor CM, Glassman AH, Harrison DJ. Pharmacoeconomic analysis of sertraline treatment of depression in patients with unstable angina or a recent myocardial infarction. J Clin Psychiatry 2005;66:346-52.

34. Kirsch I, Deacon BJ, Huedo-Medina TB, et al. Initial severity and antidepressant benefits: a meta-analysis of data submitted to the Food and Drug Administration. PLoS Med 2008;5(2):e45.

35. Pham B, Lawson M, Klassen $\mathrm{T}$, et al. Language of publication restrictions gave different results depending on whether the intervention was conventional or complementary. JClin Epidemiol 2005;58:769-76.

36. Moher D, Pham B, Klassen TP, et al. What contributions do languages other than English make on the results of meta-analyses? J Clin Epidemiol 2000;53:964-72.

37. Zimmerman $M$, Posternak $M$, Chelminski I. Implications of using different cutoffs on symptom severity scales to define remission from depression. Int Clin Psychopharmacol 2004;I9:215-20.

38. Lieberman JA, Greenhouse J, Hamer RM, et al. Comparing the effects of antidepressants: consensus guidelines for evaluating quantitative reviews of antidepressant efficacy. Neuropsychopharmacology 2005;30:445-6o.

39. Turner EH, Matthews AM, Linardatos E, et al. Selective publication of antidepressant trials and its influence on apparent efficacy. N Engl J Med 2008;358:252-60.

40. McAuley L, Pham B, Tugwell P, et al. Does the inclusion of grey literature influence the estimates of intervention effectiveness reported in meta-analyses? Lancet 2000 356:1228-3I.

4I. Lexchin J, Bero LA, Djulbegovic D, et al. Pharmaceutical industry sponsorship and research outcome and quality: a systematic review. BMJ 2003;326:II67-70.

42. Zimmerman M, Mattia J, Posternak M. Are subjects in pharmacological treatment trials of depression representative of patients in routine clinical practice? Am J Psychiatry 2002;159:469-73.

Correspondence to: Dr. Dorian Deshauer, Institute of Mental Health Research, II45 Carling Ave., Ottawa ON KIZ $7 K_{4}$; fax6r3233-5756; deshaueri@sympatico.ca 